\title{
Ischaemic neuropathy of the lumbosacral plexus following intragluteal injection
}

\author{
M STÖHR, J DICHGANS, AND D DÖRSTELMANN \\ From the Department of Neurology, University of Tübingen and the Municipal Hospital of Pforzheim, \\ West Germany
}

SUMmaRY A lesion of the lumbo sacral plexus may result from an inadvertent intra-arterial injection of vasotoxic drugs into one of the gluteal arteries. Symptoms and follow-up of three cases are reported. The neuropathy is attributed to a toxic endarteritis with retrograde propagation of spasm and thrombosis. Swelling and bluish discoloration of the buttocks ("embolia cutis medicamentosa") as well as an impaired circulation in the homolateral leg are associated with the neurological syndrome in fully developed cases and makes possible a correct diagnosis.

The obstruction of a main artery by embolism, thrombosis or following trauma may lead to ischaemic neuropathy. The neurological syndrome, predominantly sensory impairment and (more rarely) paralysis, or in milder cases pain and paraesthesia, depends upon the duration of ischaemia and collateral blood supply. ${ }^{1-3}$ If the ischaemia is of short duration a rapid and complete recovery of nerve functions will occur in most cases, but ischaemia of a longer duration can lead to permanent structural damage. ${ }^{24}$ Since the oxygen turn-over of the peripheral nerve is rather low and blood supply is abundant, ischaemic neuropathies will rarely occur if only one of the main arteries or only some, but not all of the distal branches of the nerve vessels are obstructed. However, partial or total segmental necrosis of nerves regularly occurs if microembolism, microthrombosis or spasms obstruct large portions of the epineural and perineural plexus. ${ }^{15}$ This mechanism is responsible for cases of neuropathies after intra-arterial injection of angiotoxic substances, for example into the brachial artery, ${ }^{6} 7$ the inferior gluteal $\operatorname{artery}^{8-10}$ and the umbilical artery of the newborn. ${ }^{11} 12$

An inadvertent injection of vasotoxic drugs into one of the gluteal arteries may also result in a toxic angiopathy with ischaemic damage of the sciatic or gluteal nerves. With the retro-

Address for reprint requests: Manfred Stöhr, MD Liebermeisterstr 18-20, Neurologische Universitätsklinik, D-7400 Tübingen-1, West Germany.

Accepted 13 March 1980 grade propagation of angiospasms and thrombosis, the homolateral lumbosacral plexus can suffer ischaemic damage, as observed in three cases.

CASE REPORTS

Case 1 (BF, a 42 year old male): an injection of about $4.5 \mathrm{ml}$ Ultrademoplas $(500 \mathrm{mg}$ Phenylbutazon-Natrium, $500 \mathrm{mg}$ Aminophenazon, $45 \mathrm{mg}$ Lidocain- $\mathrm{HCl}, \quad 4.5 \mathrm{mg}$ Dexamethason, $9 \mathrm{mg}$ Prednisolon and $2.8 \mathrm{mg}$ Cyanocobalamin) was given into the left buttock because of lowerback pain. Immediately a severe local pain was felt, lasting for about $30 \mathrm{~s}$. Ten to fifteen minutes later, the patient noticed numbness in the left foot which crept gradually upwards. Half an hour after the injection, standing and walking were no longer possible because of a severe pain as well as a weakness in the left lower limb. The neurological examination revealed a nearly complete paralysis of the left leg, including the hip-flexors and the gluteal muscles; deep tendon reflexes were absent. There was severe sensory impairment in the territories of the femoral, lateral femoral cutaneous and common peroneal nerves, with less marked sensory disturbances in the other areas of the left lower limb. There was painful swelling and bluish discoloration of the left buttock. Additional swelling at the left paravertebral region above the pelvis ("Embolia cutis medicamentosa," fig 1) occurred and was followed by a deep gangrene within a few days. The left foot appeared colder and livid. A few days later, the persistent pain in the left leg was intensified by paroxysms. On 


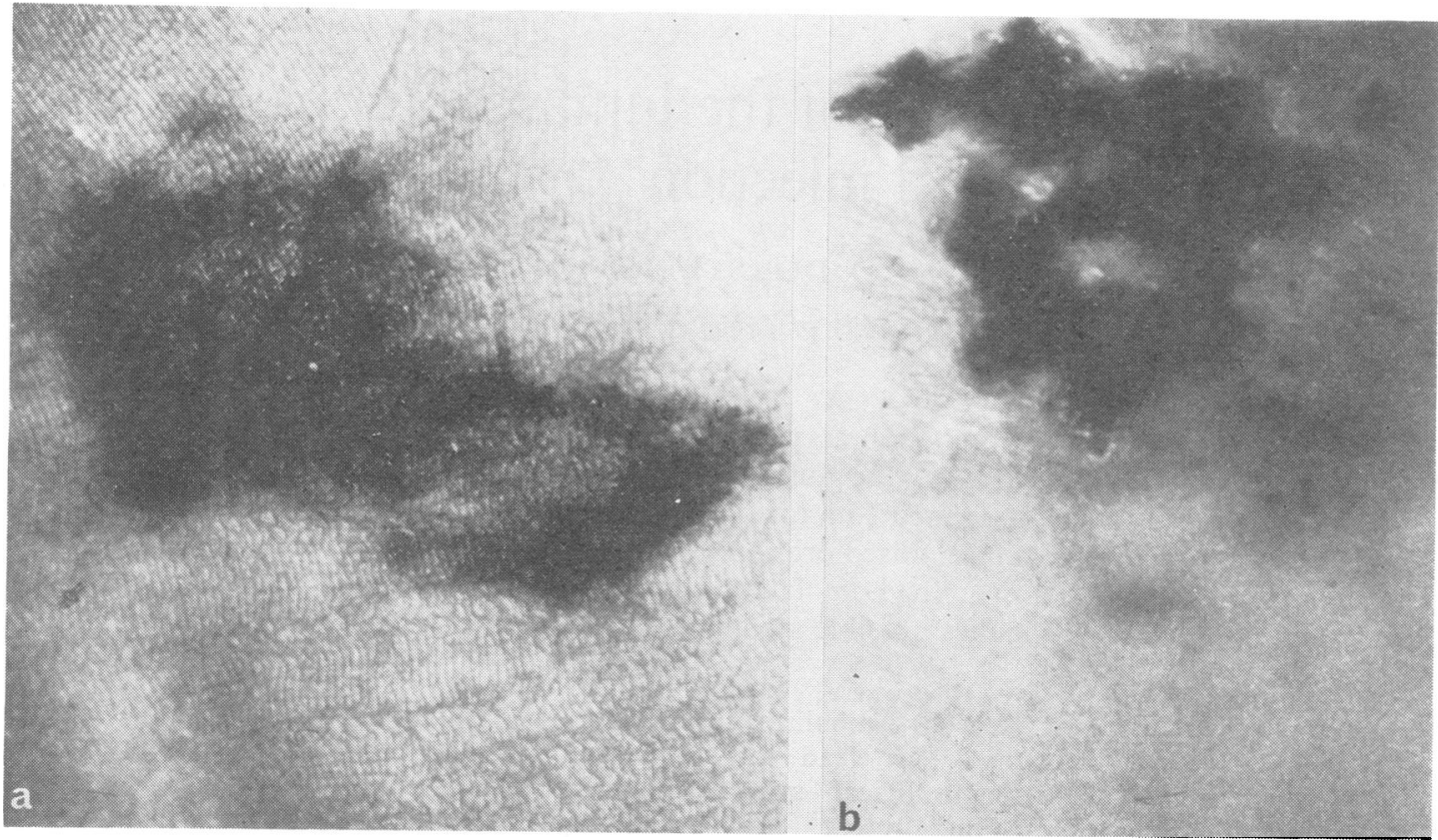

Fig 1 Swelling and bluish discoloration of the buttock (a); area of black necrotic skin, $11 \mathrm{~cm}$ above the pelvic rim and $6 \mathrm{~cm}$ laterally of the lumbar spine $(b)$.

the fifth day, the intermittently slightly improved weakness deteriorated again with one severe paroxysm of pain. In addition, micturition was intermittently disturbed and painful. The patient was not incontinent and defaecation was normal. The electromyographic examination revealed complete denervation of the quadriceps muscle and partial denervation of the other musclegroups of the lower left limb, as well as of the paravertebral muscles at the L4/L5 level. The ninhydrine-test indicated a hypohidrosis of the left foot.

General examination and blood-tests revealed no signs of diabetes mellitus or general vascular disease. Myelography was normal. The CSF protein was increased to $70 \mathrm{mg} / \mathrm{dl}$; further CSF examinations were normal.

One year later, pain had considerably decreased, but was still present, mainly in the anterior aspect of the thigh, and was aggravated by walking. Neurological examination revealed severe paresis of the extensors of the knee, foot and toes, moderate paresis of the hip flexors and slight paresis of the other muscle-groups (including the gluteal muscles). There was moderate hypaesthesia combined with hyperpathia within the territories of the femoral, lateral femoral cutaneus and common peroneal nerves. Arterial pulses of the femoral and popliteal arteries were slightly weaker on the left side. The skin temperature of the left foot was reduced by $1^{\circ} \mathrm{C}$. The oscillogram showed signs of a compensated arterial obstruction. Diagnosis: Ischaemic neuropathy of the left lumbosacral plexus with electromyographical signs of root involvement. Case 2 (WH, a 38 year old male): One ampoule Delphimix (600 mg Phenylbutazon-Natrium, 6 $\mathrm{mg}$ Cinchocain, $40 \mathrm{mg}$ Triamcinolon-diacetat, 1 $\mathrm{mg}$ Cyanocobalamin) was injected into the left buttock, because of lower back pain. Five to six hours later the patient awoke from sleep because of a numbness in the left leg. Another six hours later he experienced severe waxing and waning pain predominantly at the anterior aspect of the thigh and he was no longer able to stand. The patient was admitted to the hospital, where a painful swelling and bluish discoloration of the skin were observed at the upper part of the buttock. There was a severe paresis of the flexors and adductors of the hip and of the extensors of the knee, as well as marked hypaesthesia and hyperpathia anteromedially at the thigh were found. For several weeks pain was almost totally resistant to analgesic drugs. Pain disappeared only slowly in the course of the next two years. General examination and blood tests were normal.

A follow-up examination two years later 
revealed slight residual paresis of the above mentioned muscle groups as well as marked hypaesthesia on the medial aspect of the knee. Knee-jerk was diminished and adductor reflex was absent. The electromyographical investigation showed signs of partial denervation of the iliopsoas, adductor longus and rectus femoris muscles. No abnormalities were found in the paravertebral muscles (L3/L4). Diagnosis: Ischaemic neuropathy of the left lumbar plexus. Case 3 (BA, a 13 month old male): An injection of penicillin into the left buttock was followed by a painful local swelling, and a flaccid paralysis of the left lower limb. The neurological examination 4.5 months later revealed a still complete paresis of the whole leg, except for a weak residual innervation of the toe-flexors (fig 2). Deep tendon reflexes were absent in the left, but were present in the right leg. There was no reaction to painful stimuli in the left foot and lower leg.

EMG examination and electrical nerve stimulation showed nearly complete denervation of the long and short flexors of the toes, as well as complete denervation of the gluteal, quadriceps,

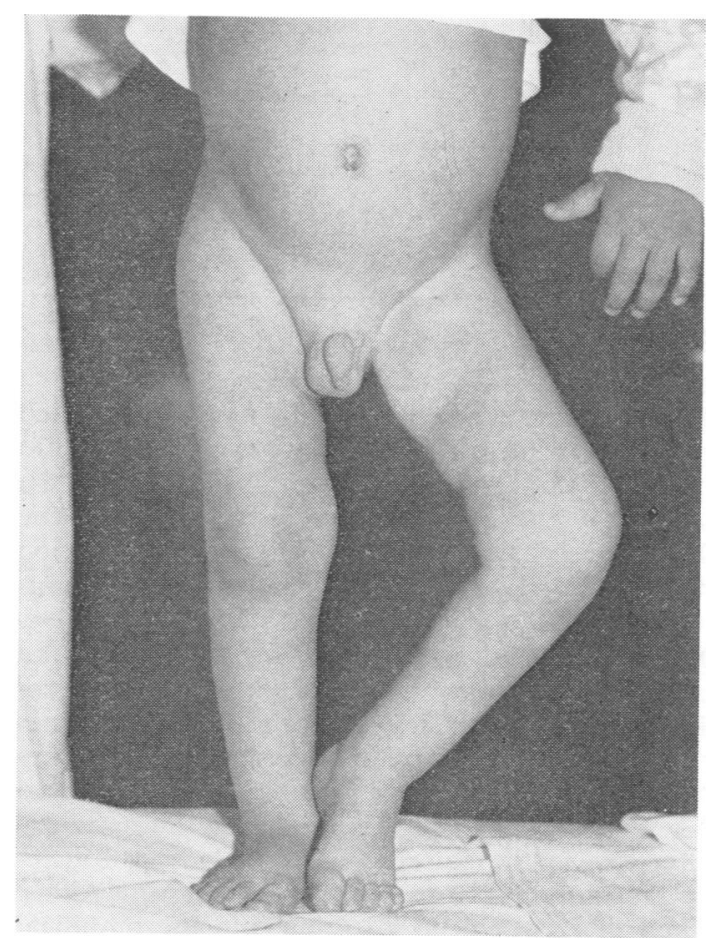

Fig 2 Case 3, 4.5 months after the injection. Nearly complete paresis of the left lower limb. tibialis anterior and soleus muscles. There were no signs of denervation in the paraspinal muscles (L3-L5). General examination, blood tests, CSF and X-rays of the pelvis and the spine were found to be normal. Diagnosis: Ischaemic neuropathy of the left lumbosacral plexus.

\section{Discussion}

Lesions of the lumbosacral plexus following an intragluteal drug injection cannot be explained by a direct mechanism, such as toxic neuropathy of the sciatic and gluteal nerves. The damage, because of its distance from the site of injection, suggests the importance of a vascular factor. An inadvertent injection of vasotoxic or crystalline drugs into the inferior gluteal artery, which supplies the proximal segment of the sciatic nerve, is known occasionally to result in a sciatic nerve lesion. ${ }^{8913}$ The underlying cause is most likely to be either embolic obstruction by crystals ${ }^{14}$ or a toxic endarteritis with spasms and thrombosis, which spread to the epineural and perineural blood vessels and cause segmental infarction.

Since the skin of the buttock is largely supplied by the same artery, it is not surprising that these particular lesions of the sciatic nerve are invariably associated with a painful swelling and a bluish discoloration of the buttock, which is then sometimes followed by gangrene ("embolia cutis medicamentosa"). 8101314

A similar mechanism could be responsible for lumbosacral plexus lesions, if a retrograde propagation of spasm and thrombosis occurs. Some observations are in favour of such a possibility. Homolateral gangrene of rectum, bladder, penis, scrotum and vagina have been described following an intragluteal injection ${ }^{81315}$ and suggest a circulatory disturbance within the distribution of the internal iliac artery as their possible cause. Provided that a still more extensive retrograde propagation of the toxic angiopathy occurs, the external iliac artery may be occluded in addition, with subsequent ischaemia of the lower limb. ${ }^{16}{ }_{1 i}$ Since the lumbosacral plexus receives its blood supply from branches of the iliac arteries (fig 3) it is reasonable to assume that lumbosacral plexus lesions may be another consequence of such a wide-spread toxic angiopathy. In one of our cases (BF) a deep gangrene of the skin above the pelvis (fig 1) developed within the distribution of the fourth lumbar artery. This artery anastomises with the iliolumbal artery. The circulatory disturbance even in this proximal branch of the internal iliac artery suggests a widespread retrograde propagation of the toxic angiopathy. 

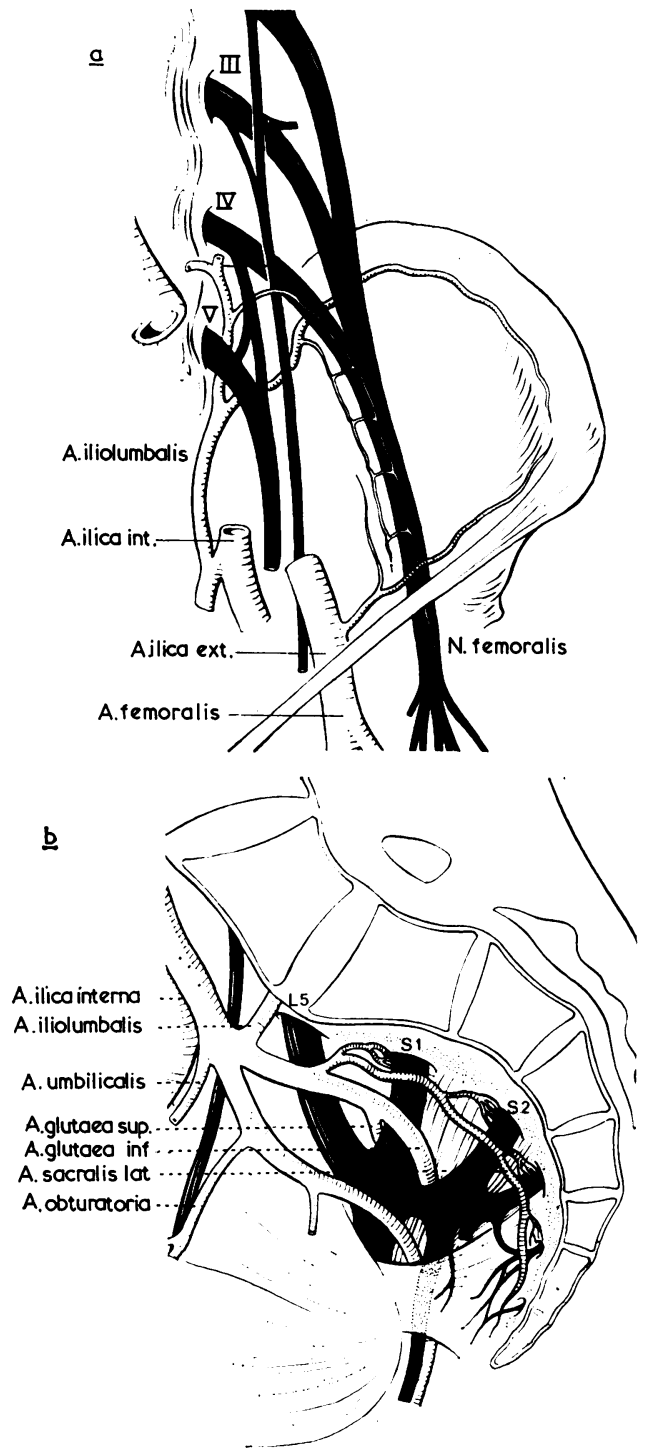

Fig 3 Blood supply of the lumbosacral plexus by branches of the iliac arteries. (From Stöhr, M.: Iatrogene Nervenläsionen. G. Thieme, Stuttgart, 1980.)

Some cases reported earlier in the literature may be explained by the assumption of the same mechanism. A flaccid monoplegia of the ipsilateral lower limb after an intragluteal injection was first described by Dereux and Ernst, ${ }^{18}$ a six year old child. Vasilescu and Stamatoiu ${ }^{16}$ reported four cases of "femoral nerve palsy." In one case the femoral nerve palsy was combined with an obturator nerve palsy. Paresis invariably followed an injection into the ipsilateral buttock and was accompanied by immediate severe pain, discoloration of the buttock and a circulatory disturbance in the leg.

Regarding the distribution of the neurological signs in these and our own cases we can differentiate three patterns of plexus damage, involving (1) the lumbar plexus or its femoral branch, or (2) the lumbar and sacral plexus, or (3) the lumbosacral plexus including some lumbosacral nerve roots (table). In very rare instances, the toxic angiopathy following an intraarterial injection in gluteal arteries can spread to the aortic bifurcation and result in a flaccid paraplegia. ${ }^{1920}$

Table Various neurological syndromes following an inadvertent drug injection into one of the gluteal arteries

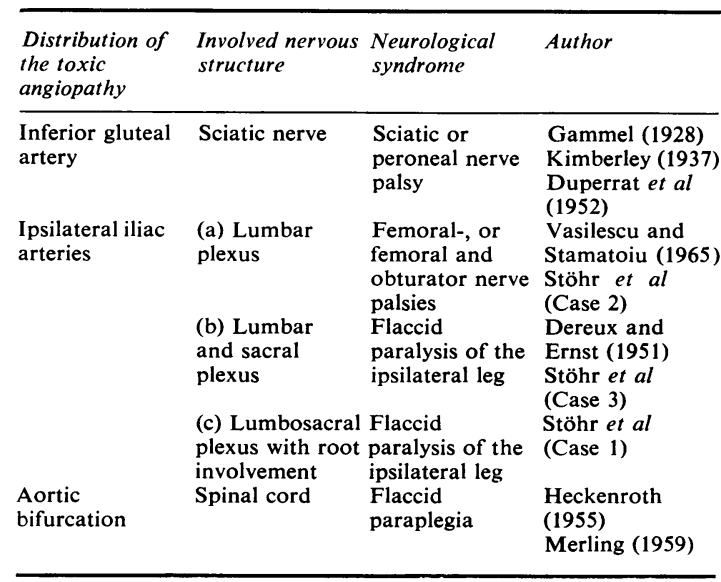

The ischaemic plexopathies following intraarterial injection in gluteal arteries exhibit striking similarities with a syndrome in newborns, which results from an injection of vasotoxic drugs into the umbilical artery. The umbilical artery is a branch of the internal iliac artery, as are the gluteal arteries (fig 3). In this case the injection may result in a discoloration and sometimes gangrene of the buttock and in a sciatic nerve palsy. Occasionally a femoral nerve palsy and a gangrene of intrapelvic structures are associated.1112 2122 As in lumbosacral plexopathies following an intragluteal injection, the development of the neurological signs may be delayed in newborns. ${ }^{23}{ }^{24}$ There is, however, one striking difference in the pattern of nerve damage following intragluteal and intraumbilical injections. When there is a drug injection into the umbilical artery of the newborn, there is a predominant involvement of the sciatic nerve. This is probably 
due to the greater functional importance of the inferior gluteal artery at this age. Plexus lesions following an injection into the buttock however case lesions of the lumbosacrel plexus, especially concerning its femoral nerve portion. ${ }^{16}$ The same pattern has frequently been observed in postoperative plexus-lesions, where the stretching of nerves and nerve vessels appears to be the most damaging factor. ${ }^{26}$ The possibility of successful therapy of vascular occlusion due to intra-arterial injection is greater when quickly diagnosed. Intra-arterial injection may be suspected if the patient immediately complains about severe local pain and may be ascertained by aspiration of arterial blood before retracting the needle. In this situation, 5 to $10 \mathrm{ml}$ of Procaine $1 \%$ (without Suprarenin) and antispasmodic drugs such as Papaverine $(40-80 \mathrm{mg}$ in $10-20 \mathrm{ml}$ isotonic saline solution) may prevent the arterial spasms. ${ }^{727}$ In order to secure the retrograde propagation of these drugs the pressure of injection should be high. Most frequently the correct diagnosis will not be reached before the retraction of the needle. In these cases Papaverin should be given intravenously. In addition, antithrombotic therapy with heparin and sympathetic blockade are recommended.

Intra-arterial injection into one of the gluteal arteries is more likely and if it happens more hazardous if the injection is performed on the medial aspect of the buttock, near the exit of the gluteal arteries from the pelvis. Therefore an injection into the upper and outer part of the buttock is recommended not only to prevent a direct sciatic nerve lesion, but also to diminish the possibility of an intra-arterial injection. Moreover, an aspiration test is mandatory prior to every injection into the buttock. Lumbosacral plexus lesions following an injection into the buttock within a few hours are a rather typical syndrome which can hardly be confused with any other syndrome. A coincidence of intragluteal injection and lumbosacral plexus lesion without causal relation seems already very unlikely, especially unlikely when the rarity of the nontraumatic plexus lesions is considered. Moreover, there should be some evidence for another cause, which occasionally leads to an acute plexopathy, like diabetes mellitus, viral infections, haemophilia or anticoagulation therapy. Other signs of a widespread toxic angiopathy such as painful swelling and discoloration of the buttock, ipsilateral gangrene of intrapelvic structures and ischaemia of the lower limb support an ischaemic plexus-lesion following an intra-arterial drug injection.

\section{References}

1 Roberts JT. The effect of occlusive arterial diseases of the extremities on the blood supply of nerves. Experimental and clinical studies on the role of the vasa nervorum. Amer Heart $J$ 1948; 35:369-92.

2 Richards RL. Ischaemic lesions of peripheral nerves: A review. J Neurol Neurosurg Psychiat 1951; 14:76-87.

3 Schrader EA. Die Klinik der arteriellen Thrombosen im Beckenbereich. Springer: Berlin, 1955.

4 Haimovici H. Peripheral arterial embolism: a study of 330 unselected cases of embolism of the extremities. Angiology 1950; 1:20-45.

5 Asbury AK. Ischemic disorders of peripheral nerve. In: Vinken PJ, Bruyn GW (eds). Handbook of clinical neurology 1970; vol. 8,2. North Holland Publ. Co. Amsterdam.

6 Cohen SM. Accidental intra-arterial injection of drugs. Lancet 1948; 255/2:409-17.

7 Chase RA. Surgery of the hand. New Eng J Med 1972; 287:1227-34.

8 Gammel JA. Local accidents following the intramuscular administration of salts of the heavy metals: Report of two cases of embolia cutis medicamentosa. Arch Derm 1928; 18:210-223.

9 Duperrat B, Béhaque P, Koff. Dermite livédoide de Nicolau, névralgie sciatique et ischémie du membre inférieur après une injection fessière de bismuth huileux. Sem Hop 1952; 28:660-1.

10 Santler R, Ebner H, Mischer P. Embolia cutis medicamentosa. Hautarzt 1972; 23:530-4.

11 Mills WG. A new neonatal syndrome. Brit Med J 1949; 2:464-6.

12 Hudson FP, McCandless A, O'Malley AG. Sciatic paralysis in newborn infants. Brit Med J 1950; 1:223-5.

13 Kimberley LW. Accidental intra-arterial injection of bismuth by X-ray in the arterioles of the penis. Amer J Syph 1937; 22:364-7.

14 Freudenthal W. Lokales embolisches BismogenolExanthem. Arch Derm Syph 1924; 147:155-60.

15 Hochstetter A. Uber Probleme und Technik der intra-glutäalen Injektion. Schweiz Med Wschr $1955 ; 85: 1138-44$.

16 Vasilescu N, Stamatoiu J. Le syndrome livédoidoparalytique. Presse Med 1965; 73:1685-8.

17 Deutsch J. Schwere lokale Reaktion nach Benzathin-Penicillin. Deutsch Gesundh 1966; 2: 2433-7.

18 Dereux J, Ernst J. Monoplégie flasque du membre inférieur gauche apparue brusquement après une injection intra-fessière d'un produit arsenical. Rev Neurol 1951; 84:335-7.

19 Heckenroth J. Les paraplegies consécutives aux injections intra-musculaires fessières. Thèse, Marseille 1955.

20 Merling $M$. (cited in Vasilescu and Stamatoiu, ref. 16). 
21 Shaw NE. Neonatal sciatic palsy from injection into the umbilical cord. J Bone Joint Surg 1960; 42 B:736-41.

22 Heyer R, Giffels G. Uber die Gefahren bei Injektionen in die Nabelarterie des asphyktischen Neugeborenen. Archiv Kinderheilk 1971; 183: 43-50.

23 Fahrni WH. Neonatal sciatic palsy. J Bone Joint Surg 1950; 32 B:42-9.

24 San Agustin, Nitowsky HM, Borden JN. Neonatal sciatic palsy after umbilical vessel injection.
$J$ Pediat 1962; 60:408-13.

25 Biemond A. Femoral neuropathy. Vinken PJ, Bruyn GW, eds. In: Handbook of clinical neurology. Volume 8,2. North Holland Publishing Co., Amsterdam 1970.

26 Stöhr M. Traumatic and postoperative lesions of the lumbosacral plexus. Arch Neurol 1978; 35: 757-60.

27 Goethlin J, Olin T. Traumatic arterial spasm. An angiographic study in rabbits. Acta Radiol 1970; 10:257-70. 